\title{
Level of Knowledge about Hypertension in Cilayung Village District Jatinangor, Sumedang
}

\author{
Dian Qisthi ${ }^{1}$, Guswan Wiwaha ${ }^{2}$, Abdul Hadi Martakusumah ${ }^{3}$, Elsa Pudji Setiawati ${ }^{2}$ \\ ${ }^{1}$ Faculty of Medicine, Universitas Padjadjaran, ${ }^{2}$ Department of Public Health, Faculty of Medicine \\ Universitas Padjadjaran, ${ }^{3}$ Department of Internal Medicine, Faculty of Medicine Universitas \\ Padjadjaran/Dr. Hasan Sadikin General Hospital, Bandung, Indonesia
}

\begin{abstract}
Background: Hypertension known as a silent killer because it is often asymptomatic and causes target organ damage. Prevention of hypertension and its complications are pharmacological and non-pharmacological therapy, making holistic knowledge of hypertension is paramount to establish good behavior. This is needed by hypertensive and non-hypertensive individuals. Therefore, the study was conducted to identify any knowledge level differences between hypertensive and non-hypertensive groups.

Methods: Respondents were 116 Cilayung residents equally divided in hypertensive and non-hypertensive groups. Respondent's blood pressure was measured and they completed questionnaires during October 2012. This is an observational analytic cross-sectional study with chi-square test.

Results: The respondents' characteristics in both groups dominated by females, aged 50-59 years, housewives, with elementary school background. Most respondents in both groups had sufficient knowledge about hypertension in general, but the risk factors, treatment, and complications were still not enough. The result of the chi-square test was not significant with $\mathrm{P}=0.676$. It was due to distribute health promotion and non-matched respondents'age.

Conclusion: There is no difference in level of knowledge about hypertension between both groups in Cilayung.
\end{abstract}

Key words: Differences, hypertension, level of knowledge

\section{Introduction}

Hypertension is known as the silent killer because it is often asymptomatic. It makes people who suffer from hypertension do not realize they have hypertension until it causes fatal complications in target organs and can be life-threatening. ${ }^{1}$ Besides, nowadays the prevalence of hypertension rises in many parts of the world. ${ }^{2}$ Data from Joint National Committee (JNC) VII shows one billion people worldwide suffer from hypertension. ${ }^{2}$ In Indonesia, based on National Basic Health Research (Riskesdas) 2007, 32.2\% of the total Indonesian population suffered from hypertension or approximately 60 million people. $^{3}$ The prevalence of hypertension in West Java is $29.4 \% .^{3}$ It is higher than prevalence of hypertension in Jakarta. ${ }^{3}$
The prevention of hypertension and its complications are essential to prevent further increased morbidity and mortality due to hypertension. Therefore it is necessary to socialize the prevention of hypertension and its complications through lifestyle modifications to the public. This socialization is expected could form a good knowledge about hypertension, so there will be good habits as well, and vice versa. ${ }^{4}$ This is suitable with the study in Nigeria that showed relationship between level of knowledge with attitudes and behaviors in preventing hypertension. ${ }^{5}$ But in reality there are many erroneous opinions regarding hypertension in the community, such as the fact that some people consider hypertension as a curable disease, or that high blood pressure in the elderly is normal, and so on.

The public knowledge about hypertension

Correspondence: Dian Qisthi, Faculty of Medicine, Universitas Padjadjaran, Jalan Raya Bandung-Sumedang Km.21, Jatinangor, Sumedang, Indonesia, Phone: +6285721376696 Email: dianqisthi@gmail.com 
Dian Qisthi, Guswan Wiwaha, Abdul Hadi Martakusumah, Elsa Pudji Setiawati: Level of Knowledge about 139 Hypertension in Cilayung Village District Jatinangor, Sumedang

including diseases and hypertension depend on the health promotion program that is closely related to public education. Health promotion program are divided into two major scopes, first is the health promotion in the scope of promotive and preventive program for non-hypertensive people, and the second is the health promotion in the scope of curative and rehabilitative program for hypertensive people. ${ }^{4}$

Based on the previous study in the primary care in Jatinangor and in electronic and mass media, the current health promotion activities were dominated in the scope of curative and rehabilitative through counseling method for hypertensive people diagnosed by health care provider. Besides, health promotion activities may be ineffective and inefficient because of the health care providers have not arranged this activities in accordance with the characteristics of the target in health promotion activities. Therefore, this study was conducted to identify any knowledge level differences between hypertensive and non-hypertensive groups, and to explain the characteristics and the level of knowledge that can help health care provider in determining most appropriate health promotion program for the public.

\section{Methods}

The population of this study was 4.965 residents in 11 (eleven) Rukun Warga (RW) of Cilayung village, District Jatinangor, Sumedang. The period of this study was from February to December 2012 with data collection conducted during October. This study was approved by The Health Research Ethics Committee Faculty of Medicine Universitas Padjadjaran. Respondents were also given a written description about this study and have to sign informed consent sheetbeforejoining the study.

The sample was divided into two groups: hypertensive and non-hypertensive groups. The inclusion criteria for both groups were Cilayung village resident, willing to participate in this study, aged $\geq 18$ years, and did not have any disease that could disrupt communication. The inclusion criteria for hypertensive group was having high blood pressure according to Joint National Committee (JNC) VII criteria when measured, or had been diagnosed with hypertension by health care providers, or had ever taken antihypertensive medications. The inclusion criteria for non-hypertensive group had normal blood pressure according to Joint National Committee (JNC) VII criteria when measured in this study, never had been diagnosed with hypertension by health care providers, and never had taken antihypertensive medications.

Sample size was determined by a formula appropriate for this study which was observational analytic study with two unpaired groups. From that formula, minimum sample needed in each group was 51 respondents, but in order to anticipate data missing that might occur in the study, the number of sample in each group obtained was 58 respondents. Sampling method was probability sampling technique, with the type of simple stratified proportionate consecutive sampling.

In this study, the blood pressure of the selected respondent was measured first and then the respondent filled in the questionnaire about the characteristics of respondent and the level of knowledge in hypertension. This study used observational analytic with cross-sectional design. ${ }^{6}$ The author categorized the knowledge to good, moderate, and poor knowledge by calculating the average and standard deviation score of all respondents. And then respondents with the score above the average added by standard deviation categorized with good knowledge, respondents with the score below the average minus standard deviation categorized with poor knowledge, and respondents with score between that points categorized with moderate. Hypothesis test used was chisquare test. ${ }^{6}$

\section{Results}

Table 1 showed the characteristic of the respondents in this study. Based on the characteristics of sex and age of respondents, both groups were dominated by female respondents and 50-59 years old aged. There were more aging respondents in the hypertensive group than in the non-hypertensive group. Both groups were also dominated by respondents with elementary school as educational background and had profession as a housewife. Almost all respondents in both groups had ever heard about hypertension.

The source of information in both groups mostly came from health care providers. The new fact that found in the study was that nonhypertensive group was also well-informed about hypertension through health promotion activities with counseling method. Counseling about hypertension was obtained when the respondents in non-hypertensive group came 
Table 1 Respondent's Characteristics

\begin{tabular}{|c|c|c|}
\hline & $\begin{array}{c}\text { Hypertensive Group (\%) } \\
\text { n=58 }\end{array}$ & $\begin{array}{c}\text { Non-hypertensive Group (\%) } \\
n=58\end{array}$ \\
\hline \multicolumn{3}{|l|}{ Sex } \\
\hline Female & 87,9 & 65,5 \\
\hline Male & 12,1 & 34,5 \\
\hline \multicolumn{3}{|l|}{ Age } \\
\hline 30-39 years old & 8,6 & 25,9 \\
\hline 40-49 years old & 12,1 & 15,5 \\
\hline 50-59 years old & 32,8 & 36,2 \\
\hline $60-69$ years old & 22,4 & 17,2 \\
\hline$>69$ years old & 24,1 & 5,2 \\
\hline \multicolumn{3}{|l|}{ Educational background } \\
\hline Elementary school & 87,9 & 72,4 \\
\hline Junior high school & 5,2 & 13,8 \\
\hline Senior high school & 5,2 & 3,4 \\
\hline College & 1,7 & 10,3 \\
\hline \multicolumn{3}{|l|}{ Job } \\
\hline No job & 0 & 5,2 \\
\hline Housewife & 65,5 & 51,7 \\
\hline Farmer & 13,8 & 17,2 \\
\hline Laborer & 0 & 0 \\
\hline Entrepreneur & 17,2 & 17,2 \\
\hline Teacher & 1,7 & 5,2 \\
\hline Private company employee & 1,7 & 1,7 \\
\hline \multicolumn{3}{|l|}{ Information about hypertension } \\
\hline Ever heard about it & 98,3 & 77,6 \\
\hline Never heard about it & 1,7 & 22,4 \\
\hline \multicolumn{3}{|l|}{ Source of information } \\
\hline Never heard about it & 1,7 & 22,4 \\
\hline Family, relatives, neighbors & 29,3 & 36,2 \\
\hline $\begin{array}{l}\text { Health care services (doctors, } \\
\text { midwives, cadre) }\end{array}$ & 69 & 41,4 \\
\hline
\end{tabular}

to health care provider while they were sick.

The majority of respondents in both groups have moderate level of knowledge about hypertension. The result of the level of knowledge in both groups is shown in Table 2 . The result of the chi-square analysis to see whether there was any difference in the level of knowledge of hypertension in both groups is shown in Table 3. P value obtained in this study was $0.676(\mathrm{P}>0.05)$. It means there was no any difference in the level of knowledge in hypertension between both groups.

Both of groups had moderate level of knowledge about hypertension. But in the hypertensive group, there were fewer respondents with poor level of knowledge than in non-hypertensive group who also had poor level of knowledge about hypertension. From the result of all respondents' answer in questionnaire about knowledge of 
Dian Qisthi, Guswan Wiwaha, Abdul Hadi Martakusumah, Elsa Pudji Setiawati: Level of Knowledge about 141 Hypertension in Cilayung Village District Jatinangor, Sumedang

Table 1 Respondent's Characteristics

\begin{tabular}{lccc}
\hline Level of Knowledge & $\begin{array}{c}\text { Hypertensive Group (\%) } \\
\mathbf{n = 5 8}\end{array}$ & $\begin{array}{c}\text { Non-hypertensive Group (\%) } \\
\mathbf{n = 5 8}\end{array}$ & p value \\
\hline Poor & 12,1 & 17,2 & 0,676 \\
Moderate & 72,4 & 65,5 & \\
Good & 15,5 & 17,2 & \\
\hline
\end{tabular}

hypertension, there were over $60 \%$ of respondents answered correctly to questions concerning the definition and epidemiology of hypertension.

While in the question about the risk factors of hypertension, there are more than $50 \%$ of respondents were not aware that frequent alcohol consumption, over weight, old age, and a family history of hypertension may increase the risk of developing hypertension. However, most respondents knew that stress or irritability and salty food (excessive salt intake) could increase the risk of hypertension.

From respondents' answers of both groups in the question about treatment and complications showed that there were still few people who knew the complications of hypertension and that the treatment of hypertension should be for lifetime. These findings suggest that knowledge about hypertension was still not enough, especially regarding risk factors, treatment, and complications.

While in the other question about the risk factors, treatment, and complication of hypertension as described above, there were still few people could answer the questions correctly. These findings suggest that knowledge about hypertension was still not enough, especially regarding risk factors, treatment, and complications.

\section{Discussions}

In this study hypertensive group was dominated by female respondents. This was not in accordance with article about further analysis of Indonesian health survey 2007 that said hypertension is more common in male. ${ }^{3}$ This might occur because of the timing of data collection in this study was noon until late afternoon. At that time, there were more females at home as housewives, while males were not at home to do their job outside home. Hypertensive group was dominated by respondents aged 50-59 years old, and there were also more respondents aged over 59 years in this group than in non-hypertensive group. This was consistent with previous surveys such as the Joint National Committee (JNC) VII, American Heart Association, and health profile of West Java who said the risk of hypertension is also increasing if the age is increasing. ${ }^{2,7-8}$

In the hypertensive group, most of the respondents had elementary school as formal educational background and worked as housewives. The higher the educational background of respondents, the fewer the number of respondents with that background in the hypertensive group. This was consistent with the result of further analysis of Indonesian health survey 2007, that indicates the incidence of hypertension is higher in people with low levels of educational background.3 Respondents in hypertensive group were dominated by housewives. This is in line with a survey of hypertension, which suggests that high blood pressure affects more people with light work. ${ }^{3}$ In addition, it can also be caused by the timing of data collection of this study, which was from noon until late afternoon, when more females were at home than males.

Results of this study was not significant. It was different from a similar study conducted in Pakistan. ${ }^{9}$ This difference might be due to the differences of sample characteristics between the research in Pakistan and in Jatinangor.9 Research in Pakistan was carried out in urban areas with a large sample size, which were 440 people, while the research in Jatinangor wasn't carried out in urban areas and the sample size was $116 .{ }^{9}$ In addition, it could also be caused by the new facts discovered during this study. The fact that health promotion activities for hypertension through counseling method not only received by the hypertensive group, but also by non-hypertensive group. As previously described, counseling was obtained by the non-hypertensive group when they came to health care providers (such as doctors and nurses) when they were sick.

Furthermore this study also found that the method of counseling through the mass media (such as the use of leaflets and posters) 
was less effective and less efficient. This was demonstrated by the absence of the respondents who had received information about hypertension through the mass media. This could happen because of the quantity, quality, and distribution were still less. Furthermore, the results was not significant due to absence of the matching process in age characteristic between the two groups of this study. This matching process can't be carried out due to insufficient time to do so.

In conclusion, the characteristics of hypertensive and non-hypertensive Cilayung villagers were not so different, they were dominated with female, 50-59 years of age, elementary school as educational background, housewife, and most of them had ever received information about hypertension from health care providers. Respondents in hypertensive and non-hypertensive groups had moderate level of knowledge about hypertension. And there was no any difference level of knowledge in hypertension between hypertensive and non-hypertensive groups in Cilayung.

From this study, author suggests that the awareness of health care providers for health promotion activities in the scope of promotion and prevention services with counseling methods should be increased for getting more targets in public, not just people who come to the health service. That's because almost all respondents in this study knew about hypertension from the counseling that they got from general physician they met when they got sick. The general physician give them the information about their blood pressure when examining the vital signs.

While the health promotion activities with mass media (public) should increase the quality by making more interesting design, increasing the quantity, and expanding the distribution. The whole health promotion activities can be focused on education about risk factors, treatment, and complications of hypertension because knowledge of these subjects was still not enough. In addition, further research is necessary to analyze the attitudes and behavior of people towards hypertension. This research was conducted to see whether the attitudes and behaviors formed are in accordance with the level of knowledge. And another further research needs to be done is to analyze the difference level of knowledge, attitudes, and behaviors in hypertension among people who have risks of hypertension and those who do not have risks.

\section{References}

1. Kaplan N. Kaplan's clinical hypertension. 9th ed. Texas: Lipincot William \& Wilkins; 2006.

2. Lenfant C, Chobanian AV, Jones DW, Roccella EJ. Seventh report of the Joint National Committee on the Prevention, detection, evaluation, and treatment of high blood pressure (JNC 7). Circulation. 2003;107(24):2993-4.

3. Rahajeng E, Tuminah S. Prevalensi hipertensi dan determinannya di Indonesia. Majalah Kedokteran Indonesia. 2009;59:580-7.

4. Notoatmodjo S. Promosi kesehatan teori dan aplikasi. Jakarta: PT Rineka Cipta; 2010.

5. Lyalomhe GBS, Lyalomhe SI. Hypertensionrelated knowledge, attitudes and life-style practices among hypertensive patients in Sub-urban Nigerian community. J Public Health Epidemiol. 2010;2(4):71-7.

6. Dahlan MS. Statistik untuk kedokteran dan kesehatan. 5th ed. Jakarta: Salemba Medika; 2011.

7. Roger VL, Go AS, Llyod-Jones DM, Benjamin EJ, Berry JD, Borden WB. Heart disease and stroke statistic - 2012 update : a report from The American Heart Association. Circulation. 2011;125:e88-e96.

8. Suseda. Profil Kesehatan Jawa Barat 2007. Bandung: Badan Pusat Statistik; 2008.

9. Zafar SN, Gowani SA, Irani FA, Ishaq M. Awareness of the risk factors, presenting features, and complication of hypertension among hypertensives and normotensives. J Pak Med Assoc. 2008;58(12):711-5. 